\title{
Vial Rinser for Reuse of Scintillation Vials
}

While some users of liquid seintillation counting vials discard each vial after use, others prefer to wash and reuse their vials. A typical automatic laboratory washing machine can wash 100 vials in one load at low cost. It seems unwise to empty radioative vials into a waste bottle and then load them directly into the machine, as the adhering radioactivity is likely to contaminate clean areas in the wash room. Since washers generally recycle part of the wash water, radioartivity can accumulate to an appreciable extent in the machine's reservoir. Wo prerinse each vial with acqueous detergent solution prior to loading the vials into the washing machine. The section below describes the rinsing device and gives some idea of its effectiveness.

Cold water from the house line is led to an clectrically operated solenoid valve, then to a garden spraving deviee, then to the rinser shown in Fig. 1. The spraying deviee such as the (ortho "spray-ette 4") is of the type that is ordinarily attached to a garden hose for spraying a conecntrated solution of insectirille or weerl poison. As the water from the houke supply goes through the sprayere, it dilutes (in our case) a concentrated solution of detergent and the mixture spurts out through the rinser, which has a central jet at the bottom and three side holes 1.41 in the immer wall. When an emptied ratioactive vial is placed mouth down in the rinser, and the solenoid valre is activated by a foot switeh, the jets of detergent solution rinse the imner. and part of the outer, surfaces of the vial. More details follow.

The cold water supply should exit through an adjustable valve, to enable shutting off the water when the system is not in use, and to arljust the flow rate. The flow of water should be sufficient to jroduce a reasonable jet in the rincer; too low a flow will prevent the aspirator effect needed for the spray action. The low flow rate will be recognized by entranee of water into the spray bottle and leakage out the top. The vertical jet stream should be strong cnough to hit the bottom of the vial but without hurling the vial out of the rinser. A large solenoid valve is needed, such as the skinner Electric L2DA4150 (a $1 / 2$ in. orifice valve).

The solenoid valve is comnected to the water by $1 / 4$ in. polyethyleme tubing by means of plastic compression fittings, but a few pipe fittings will be needed to go from this tubing to the spray bottle. which is fittert 


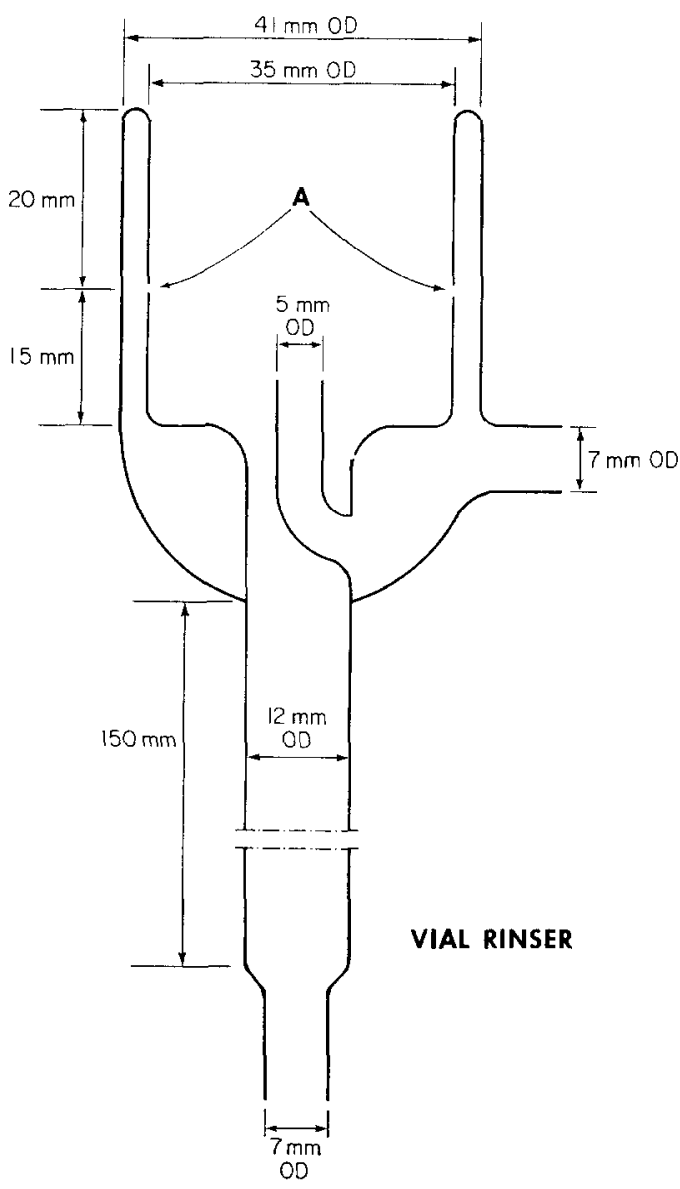

FIG. 1. Scintillation vial rinser. The water-detergent mixture enters through the side arm on the right and spurts out through the vertical center tube and three holes, $A$ (only two of which are shown). The holes are made in the inner tube before sealing it to the outer tube by "drilling" with a heated tungsten wire yo in. diam. The entire device is mounted on a small support stand in the sink and a rubber tube attached to the bottom earries the rinse liquid directly into the sink drain. A small washer-shaped piece of metal screening (not shown) rests on the bottom of the inner section and the seintillation vial mouth rests on it during the rinsing operation. The rinser may be obtained from our glassblower, Mr. Peter Severn, 2221 E. Engineering, University of Michigan.

with a hose connection. These fittings can be obtained from hardware stores, which also sell the lawn sprayer. Our sprayer is of the 4-gal size, which we fill with 8 fluid oz of Micro (International Products Corp., Trenton, NJ) and then with water to the top of the bottle. The sprayer 
bottle is not actually $4 \mathrm{gal}$ in volume, but delivers 4 gal of diluted detergent. Lately many detergent concentrates for washing laboratory glassware have been offered and it is possible that another brand would be better. The sprayer outlet loads to Tygon tubing to the rinser. It is necessary to plug the finger hole on the spraver with a small stopper Arthur H. Thomas Co. microstopper!.

The sprayer normally leaks a small amount of water (not detergent) from the air intake, so we cover this with aluminum foil and support the sprayer above the sink.

Users should be warned to avoid losing the small wire sereen at the bottom of the jet.

Tests of the effectiveness of rinsing were made by pouring out the contents of highly radioactive vials (into storage bottles for later disposal), rinsing the vials as described above, storing the rials briefly mouth down on a paper towel, then adding seintillation solvent and recounting. The solvent used consisted of $0.5 \mathrm{ml}$ water and $11 \mathrm{ml}$ of a toluene seintillant containing Bio-Solv BBS-3 (Beckman Instruments, Inc.). When vials previously filled with high levels of tritium compounds were rinsed and counted, no activity could be detected. When similar vials containing ${ }^{32} \mathrm{P}$ compounds were counted, residual activity ranging hetween $0.02 \%$ and $1.6 \%$ was found. Fridently some substanees are adsorbed fairly strongly but are removed completely by the hot detergent used in the washing machine. At any rate, the rinsing device removes the loosely bound "P that would otherwise contaminate the washing area. It is probably safest to let ${ }^{32} \mathrm{P}$ vials decay to $10,000 \mathrm{cpm}$ or less before washing them.

The use of glass for fabricating the rinser might seem dangerous on the basis of fragility, but our rinser has been used for many months with many thousands of vials without damage. No doubt a similar one could be made of metal; the dimensions should not be changed much because the spray device does not work if the resistance to flow is increased appreciably. A metal rinser built to rinse two vials simultaneously would be useful for a large laboratory. Howerer the limiting speed fartor is the time required to unserew and empty the vials.

When large numbers of vials are handled, the scintillation solvent odor becomes obnoxious. We have minimized this problem by installing a kitchen range hood above the sink (vented to an air exhaust) and by emptying the vials with a suction tube connected to the disposal bottle furnished by our Radiation Control Service. Neoprene tubing or Viton tubing is suitable for the suction tube.

We found that some lab assistants skimp on the rinse time and may 
produce incompletely rinsed glassware. We therefore installed a 2 -sec self-resetting timer switeh between the foot switch and the solenoid valve (circuit diagram available on request).

The reader might prefer to use a floor-mounted water valve (BL5000-2, T \& S Brass and Bronze Works, Westbury, L.I., N.Y.I instead of the electrically controlled water valve. This too is operated by a single push with the foot.

\section{ACKNOWLFDGMFNTS}

I am indebted to James Mullison and James Abel for derigning and building the rinse timer.

Mental Health Resetrch Institute

Norman S. Radin

University of Michigan

Ann Arbor, Michigan 48104

Receined April 9, 1973; accepled June 15, 1973 